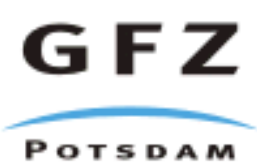

Originally published as:

Hurtig, E., Stromeyer, D. (1985): Three-dimensional modelling of crustal temperature and Moho heat flow density in Central Europe and adjacent areas. - Journal of Geodynamics, 4, 14, 63-73, 10.1016/0264-3707(85)90052-3. 


\title{
THREE-DIMENSIONAL MODELLING OF CRUSTAL TEMPERATURE AND MOHO HEAT FLOW DENSITY IN CENTRAL EUROPE AND ADJACENT AREAS
}

\author{
E. HURTIG and D. STROMEYER \\ Zentralinstitut für Physik der Erde, Telegrafenberg, DDR-1500 Potsdam, G.D.R.
}

(Accepted July 4,1985)

ABSTRACT

Hurtig, E. and Stromeyer D., 1985. Three-dimensional modelling of crustal temperature and MOHO heat flow density in Central Europe and adjacent areas. In: L. Rybach (editor), Heat Flow and Geothermal Processes. Journal of Geodynamics, 4: 63-73.

For the Central European area three-dimensional model techniques are used to estimate the temperature-depth distribution within the Earth's crust, the temperature at the crust-mantle boundary, the MOHO heat flow density, and the lateral variations of the heat production within the granitic upper crust. Regularization methods are used for the inversion of the surface heat flow density. The calculations were done for a $1 \times 1$ degree grid. Evidently, for single geothermal provinces the 200',400). $600^{\prime}$, and $800^{\circ}$ isotherms are running parallel to the crust-mantle boundary which implies that this discontinuity might be interpreted in terms of an isotherm.

\section{INTRODUCTION}

For geodynamic inverstigations it is of essential interest to have some knowledge on the temperature distribution within the Earth's crust as well as on the temperature and on the heat flow density at the crust-mantle boundary.

Cermak (1982) reviewed the attempts to estimate the MOHO heat flow for the European area and presented a MOHO heat flow density map for a grid of $2 \times 2$ degrees.

The MOHO heat flow density estimations have been done on the basis of an one-dimensional solution of the steady state heat conduction equation. This approach overemphasizes local anomalies of the heat flow density near the earth's surface. Furthermore, if there are lateral variations of the MOHO depth as well as of the thicknesses of the granitic crust and of the sedimentary layers the one-dimensional approach gives strong and unlikely 
lateral variations of the temperature in the lower crust and at the crustmantle boundary.

Test calculations showed that three-dimensional model techniques have to be applied if the dimensions of the grid for which the heat flow density and the temperature at the crust-mantle boundary are evaluated are equal or smaller than the dimensions of the lateral variations of the thicknesses of the crustal layers and of the MOHO depth.

THE DATA

Averaged for a grid of $1 \times 1$ degree the following data are used for estimating the geothermal parameters:

- Heat flow density data as given in the map of the terrestrial heat flow for Europe (Čermak and Hurtig, 1975).

- Depth of the basement using published data and maps (e.g. Jubitz, 1976; Sollogub et al., 1978).

There may be some differences in the interpretation of the nature of the basement. This can be either the surface of the cristalline basement or that of higher metamorphic rocks (lower palaeozoic rocks).

- Depth of the lower boundary of the granitic crust defined as the depth of the velocity increase from about 6.0 to $6.5 \mathrm{~km} / \mathrm{s}$. The data were taken from the published results of several authors (e.g. European Seismological Commission, 1982; Giese et al., 1973, 1974; Sollogub et al., 1978)

An error of $\pm 2-3 \mathrm{~km}$ must be taken into account.

- Depth of the crust-mantle boundary using published data (e.g. Sollogub et al., 1978; Choudhury et al., 1971; Colombo et al., 1973; Faber, 1978; Giese et al., 1973; Labrouste et al., 1968; Makris, 1977; Miller et al., 1978; Mueller et al., 1973, 1980; Recq, 1970; Sapin et al., 1974; Schütte, 1978; Weigel, 1974; Mostaanpur, 1984).

\section{METHOD OF THREE-DIMENSIONAL MODELLING}

From the mathematical point of view a three-dimensional inversion is an improperly posed problem. Therefore, regularization methods were used for the inversion of the surface heat flow density $q_{S}$ (see Stromeyer, 1984).

The basic steps of the model calculations are:

1. Estimation of the MOHO heat flow density $q_{M}$ using regularization methods based on the steady state heat conduction concept (see Stromeyer and Hurtig, 1983) 
2. Calculation of the mean MOHO heat flow density $\bar{q}_{M}$

3. Calculation of the temperature field within the earth's crust on the basis of $\bar{q}_{M}$

4. Calculation of the resulting surface heat flow density $q_{S C}$

5. Optimization of $q_{M}$ by taking the difference $q_{S}-q_{S C}$

The possible lateral variations of $q_{M}$ are limited by

$\iint\left(\frac{\partial q_{M}}{\partial x}+\frac{\partial q_{M}}{\partial y}\right)^{2} d x d y<\omega^{2}$

$\omega$ is choosen so that the optimized MOHO heat flow density $q_{M O}$ is greater than $O$

6. Calculation of the temperature field within the earth's crust on the basis of the $q_{M O}$ distribution

7. Calculation of the resulting surface heat flow density $q_{o s c}$

8 . Due to the limitation given by $\omega$ there remains a residual between $q_{\mathrm{s}}$ and $q 0 \mathrm{sc}$

9. The difference $q_{s}-q_{o s c}$ is used to optimize the source intensity within the granitic crust. Lateral variations of the source intensity are obtained.

The crustal temperature field was determined by solving the steady-state heat conduction equation

$-\operatorname{div}(K \operatorname{grad} T)=A$,

( $T$-temperature, $K$-thermal conductivity, $A$-heat source intensity) in the $(z, \lambda, \varphi)$ three-dimensional space, where $z$ is the depth, and $\lambda$ and $\varphi$ are the geographical longitude and latitude, respectively. The area studied is shown in Fig. 1. The lower boundary of this area is given by the depth of the crust mantle boundary. Equ. (1) was solved numerically by a finite difference technique for elements of the size $1 \mathrm{~km} \times 1^{\circ} \times 1$.

When treating two-and three-dimensional models the most important difficulty is connected with the estimation of such distributions of the heat source intensity $A$ and the MOHO heat flow density $q_{M}$ (necessary lower boundary condition) that the heat flow density $q_{S C}$ obtained from the calculated temperature field fits best the measured surface data $q_{s}$.

The well known energy balance

$q_{M}=q_{s}-\int A(z) d z$

describes completely the relation between $q_{S}, q_{M}$ and $A$ for one-dimensional 


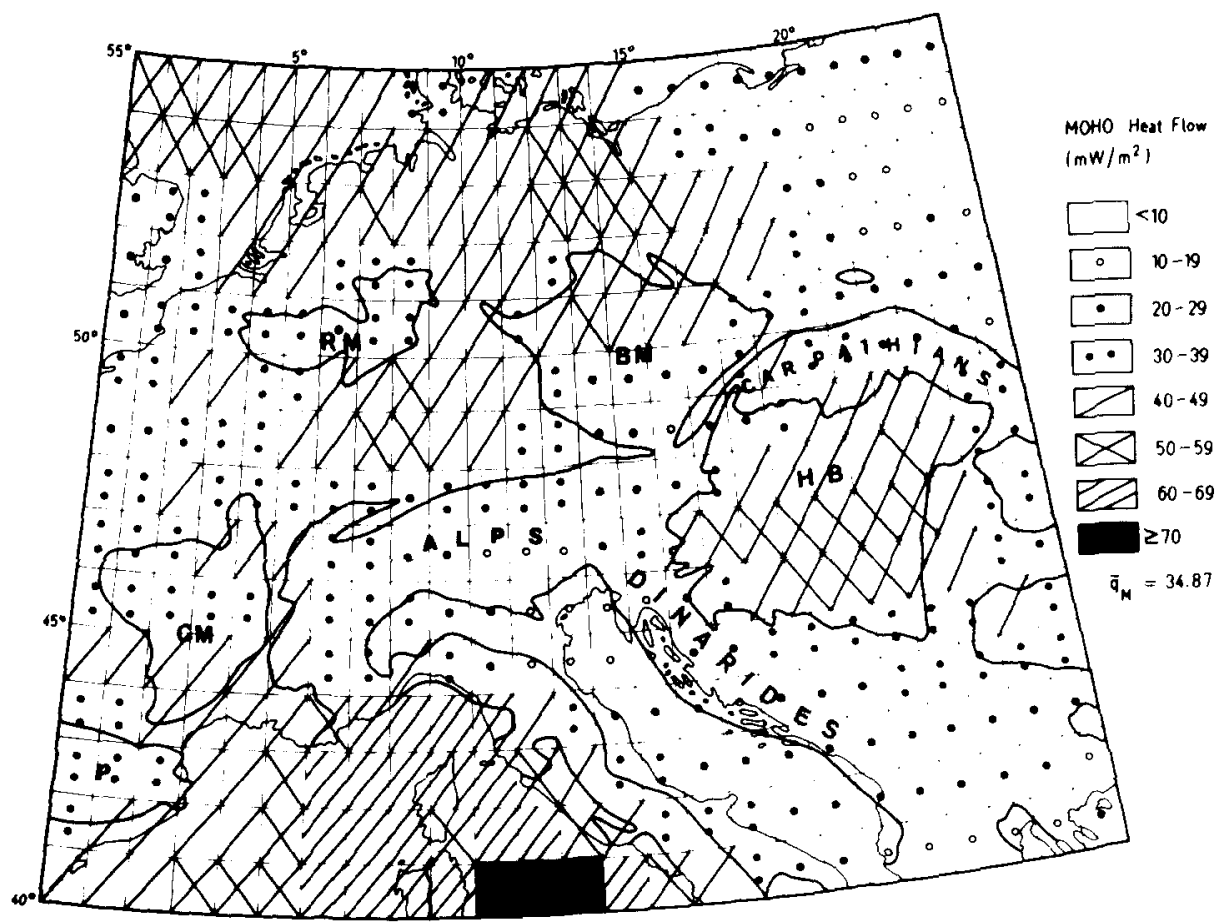

Fig. 1: Optimized MOHO heat flow density (in $\mathrm{mW} / \mathrm{m}^{2}$ ), $B M$ : Bohemian Massif; $C M$ : French Central Massif; $H B$ : Hungarian basin; $P$ : Pyrenees; $R M$ : Rhenish Massif

models, only. For all more-dimensional cases, an extension of equ. (2) gives only results about average values of these parameters.

The determination of $q_{M}$ and $A$ from $q_{S}$ is a typical inverse problem. The pointwise connection between $q_{S}, q_{M}$ and $A$ can be expressed in terms of an improperly posed linear integral equation (Stromeyer, 1984).

In the concept of finite differences this leads to a system of linear equations of the form

$q_{S}=Q q_{M}+F A$

where $q_{S}, q_{M}$ and $A$ are vectors and $Q$ and $F$ illconditioned matrices. Difficulties connected with the solution of equ. (3) are the nonuniqueness for $A$ (also for a fixed $q_{M}$ ) and the instability of its solution for many real cases. To overcome this situation a priori information must be introduced.

In this paper a well proven constrained least squares procedure was used (Stromeyer, 1984).

At first the global anomalies of $q_{S}$ were approximated by solving equ. (3) using a pre-assumed model of the source intensity $A$ (three layer crustal 


\section{TABLE 1}

Heat generation within the earth's crust (in $\mu \mathrm{W} / \mathrm{m}^{3}$ )

$\begin{array}{lccc}\text { Layer } & \text { Case 1 } & \text { Case 2 } & \text { Case 3 } \\ \text { Sediment } & 1.0 & 0.8 & 0.8 \\ \text { Granitic } & & & \\ \text { upper crust } & 2.0 & 2.25 & 1.6 \\ \text { Lower crust } & 0.5 & 0.25 & 0.25 \\ \bar{q}_{\mathbf{M}}\left(\mathrm{mW} \mathrm{m}^{2}\right) & 24.47 & 24.38 & 34.87\end{array}$

model, see table 1) and using a given bandwith for the lateral variations of $q_{M}$. This leads to the least squares problem

$\min \left\|q_{S}-F A-Q q_{M}\right\|$

where the distribution $q_{M}(\lambda, \varphi)$ is constrained by

$\left\|D_{\varphi} q_{M}+D_{;} q_{M}\right\| \leqslant \omega_{q_{M}}$

$D_{\varphi} q_{M}$ and $D_{\dot{\lambda}} q_{M}$ are the components of grad $q_{M}$ in the $\varphi$ and $\lambda$ direction, respectively.

The constant $\omega_{q_{M}}$ was choosen in such a way that the solution $q_{M O}$ (optimized MOHO heat flow density) is nonnegative for all values of $\varphi$ and $\lambda$.

Due to this lateral limitation there remains a residual between $q_{S}$ and the calculated heat flow density $\left(q_{O S C}\right)$ produced by $q_{M O}$ and $A$.

Now this difference is used to optimize the source intensity variation within the granitic crust by the same minimum problem (4) but with the above determined $q_{M O}$ distribution. Here, the constraint $\omega_{A}$ of the lateral variation

$$
\|\| D_{\varphi} A+D_{i} A \| \leqslant \omega_{A}
$$

depends on the lower and upper bounds of $A$.

From this procedure on optimized MOHO heat flow density and an optimized heat source intensity distribution are obtained which give a best fit of the observed heat flow density values near the earth's surface. The strongest lateral variations of the heat source intensity are to be expected within the upper (granitic) crust. Therefore, the optimizing of the heat source intensity was restricted to this layer. The heat source intensities of the sedimentary layer and of the lower crust were assumed to be constant. The calculations were done using a three-layer crustal model (see table 1).

From this table it becomes evident that the MOHO heat flow density depends on the heat generation model. The higher the heat generation 
within the crust the lower is the heat flow density at the MOHO and the smaller is the bandwith for its optimizing if one does not allow negative heat flow density values at the crust-mantle boundary. From the petrological point of view it seems to be reasonable to assume a mean heat generation for the upper crust of $1.6 \mu \mathrm{W} / \mathrm{m}^{3}$. This taked into consideration an exponential decrease of the heat generation within the upper crust.

Therefore, the following discussions refer to the heat generation case 3 (see table 1).

\section{RESULTS}

\section{MOHO heat flow density}

Considering the used model parameters as given in table 1 an average MOHO heat flow density $\bar{q}_{M}=34.87 \mathrm{~mW} / \mathrm{m}^{2}$ is obtained.

After optimizing of the MOHO heat flow (according to (4)) strong lateral variations of the heat flow $q_{m o}$ are to be observed.

There are some characteristic elements (see Fig. 1):

- low heat flow values at the MOHO (about $15 \mathrm{~mW} / \mathrm{m}^{2}$ and less) are valid for that part of the East European platform which is included in this study, for the Northern Adriatic and the Po Valley region.

The Bohemian Massif is characterized by values ranging between 20 and $40 \mathrm{~mW} / \mathrm{m}^{2}$.

- high MOHO heat flow values (greater than $60 \mathrm{~mW} / \mathrm{m}^{2}$ ) are typical for the Tyrrhenian Sea, the Balearic Sea and for the Carpathian basin. Increased values are also obtained for the North-German-Polish basin and the North Sea area $\left(40-60 \mathrm{~mW} / \mathrm{m}^{2}\right)$.

\section{Temperature at the crust-mantle boundary}

The temperature distribution is shown in Fig. 2.

The main features are:

- high temperature values up to about $1000^{\circ} \mathrm{C}$ are obtained along the southwestern border of the East European platform. These high temperatures are due to the great depth of the MOHO in this area of about $60 \mathrm{~km}$.

The Alps are also outlined by high temperature values. The same is valid for the Carpathians. High MOHO temperature are also obtained for the Pyrenean region. Elevated values can be observed in the North-Sea region and along the Upper Rhine Graben. 


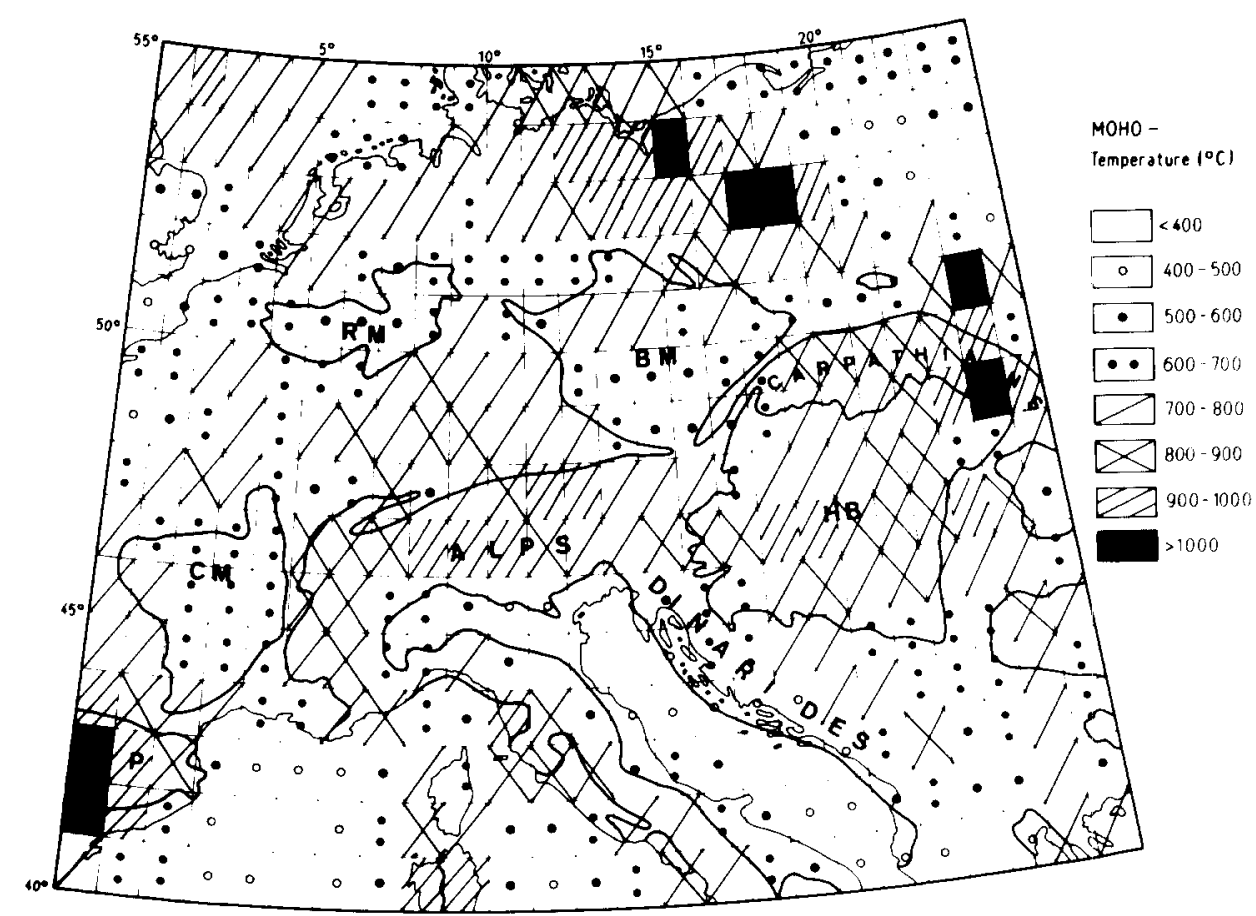

Fig. 2: Temperature at the crust-mantle boundary (in C), $B M, C M, H B, P . R M$ see Fig. 1

- Due to the thin crust the lowest temperature values (less than $500^{\circ} \mathrm{C}$ ) are obtained beneath the Balearic Sea, and the Adriatic Sea. Low temperature values are also observed beneath the East-European platform. Decreased values are obtained beneath the hercynian consolidated blocks (Rhenish Massif, Bohemian Massif, French Central Massif).

In general, it should be expected that the temperature at the crust-mantle boundary is higher the deeper the MOHO discontinuity is located. But, Fig. 3 reveals that there is a significant relation between the depth of the $600^{\circ}$ isotherm and the depth of the MOHO although the data are scattering. Details are shown for a temperature cross-section parallel to $46.5^{\circ} \mathrm{N}$ (see Fig. 4).

Evidently, the isotherms are running parallel to the course of the crustmantle boundary. A significant jump of the temperature is obtained at about $5^{\circ} \mathrm{E}$. This coincides with the transition from the Alps to the French Central Massif. A similar jump occurs near $15^{\circ} \mathrm{E}$ at the transition from the Alps to the Carpathian Basin.

Thus, it could be concluded that for single geothermal provinces the crust-mantle boundary might be interpreted in terms of an isotherm. 


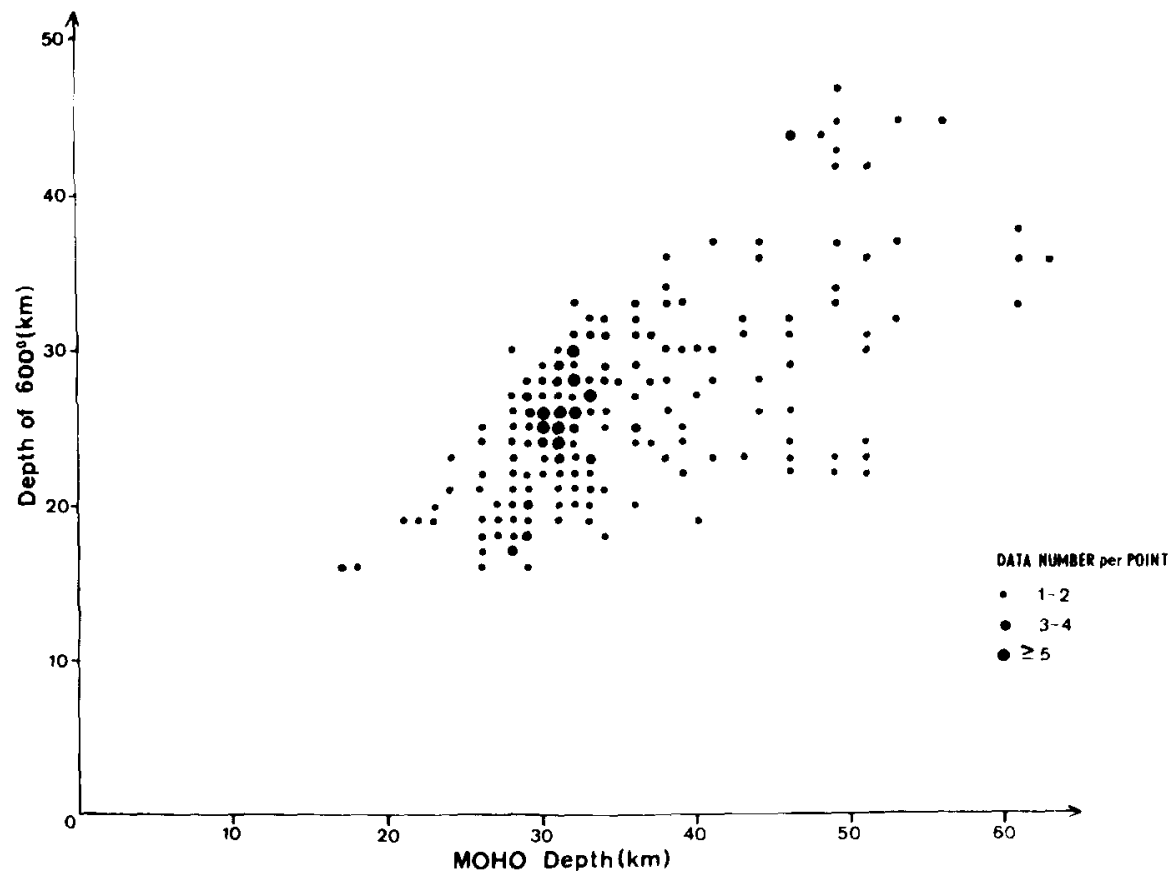

Fig. 3: Depth of the $600^{\circ} \mathrm{C}$-isotherm versus $\mathrm{MOHO}$ depth (in $\mathrm{km}$ )

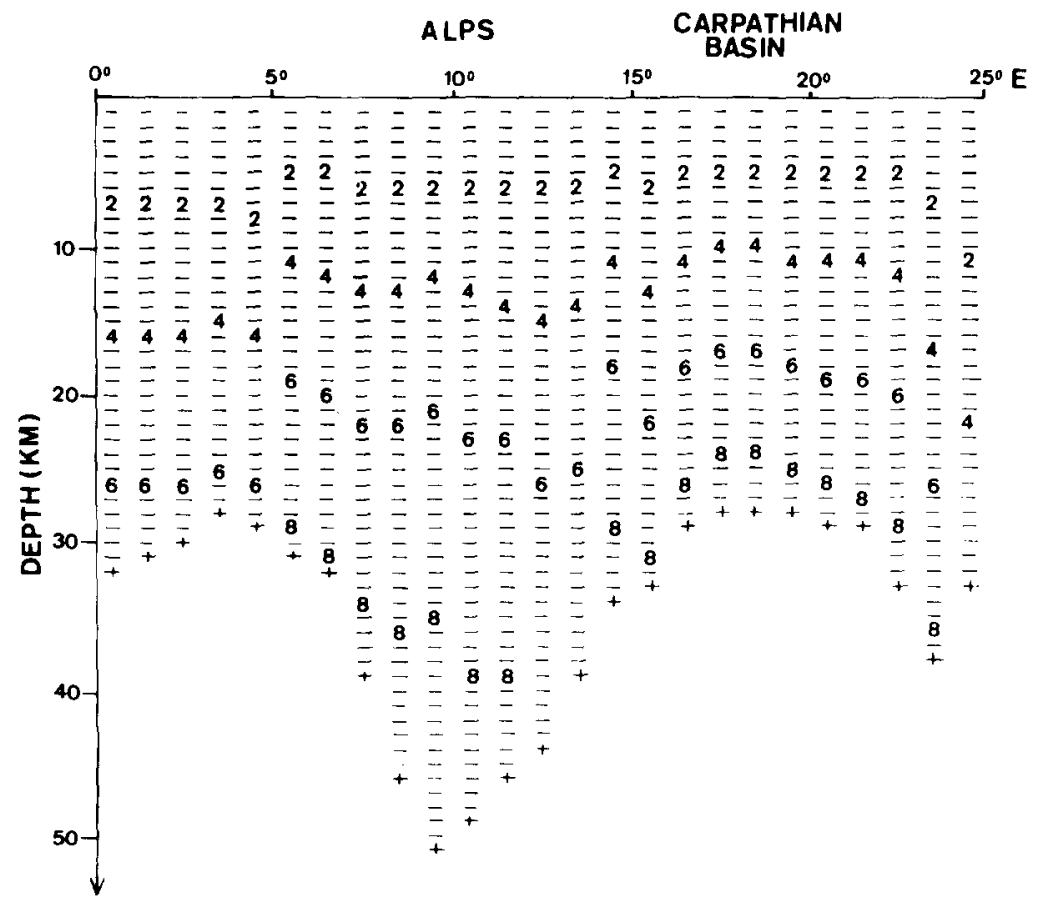

TEMPERATURE PROFILE PARALLEL $46.5^{\circ} \mathrm{N}$

Fig. 4: Temperature cross section paralles $46.5 \mathrm{~N}, 2: 200 \mathrm{C}$. $:$ : MOHO depth 


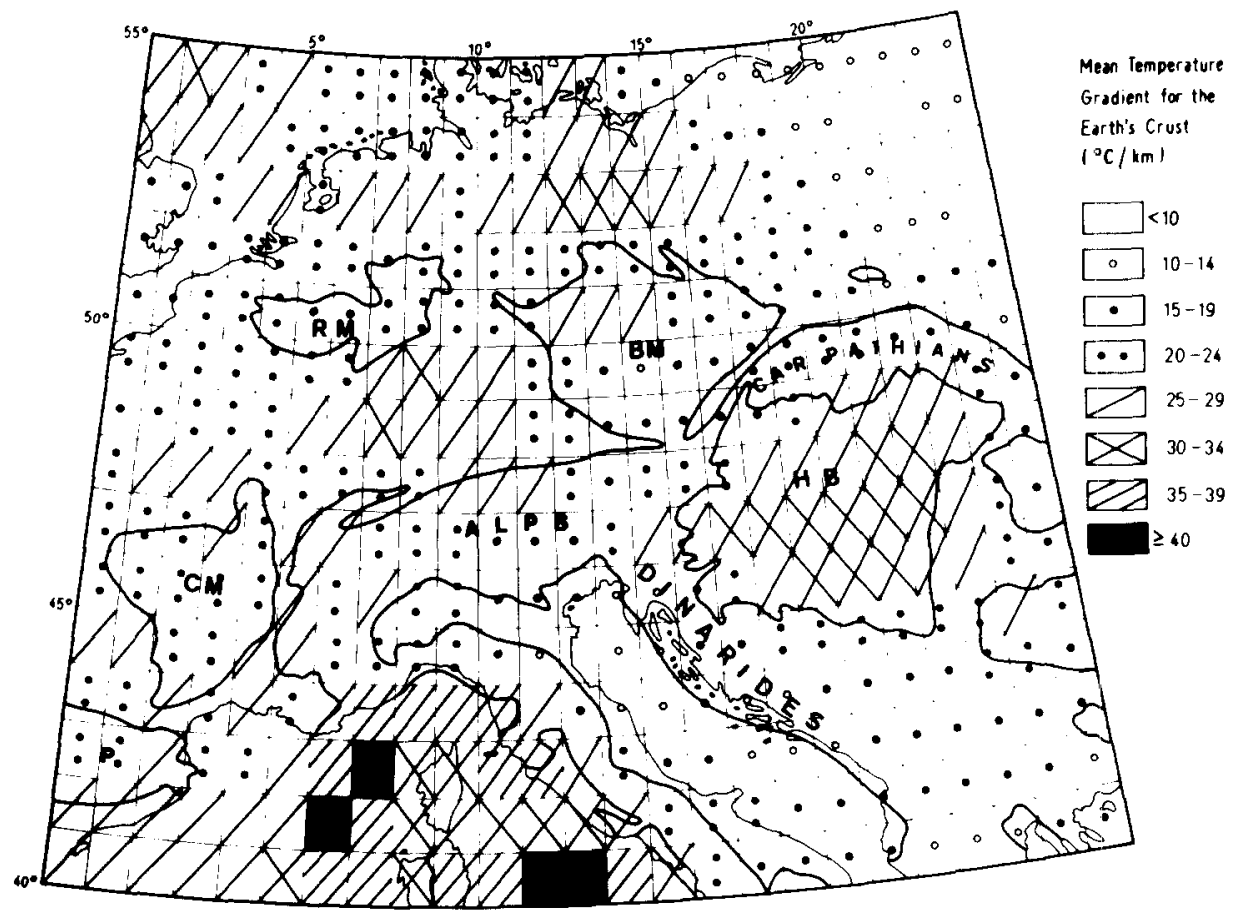

Fig. 5: Mean temperature gradient for the Earth"s crust (in $\mathrm{C} / \mathrm{km}$ ) $B M, C M, H B, P, R M$ see Fig. 1

\section{Mean-temperature gradient for the earth's crust}

The mean temperature gradient strongly reflects the thickness of the earth's crust (see Fig. 5).

Therefore, high gradients of $30^{\circ} \mathrm{C} / \mathrm{km}$ and more are obtained in Southern Europe (Balearic and Tyrrhenian Seas) and beneath the Carpathian basin.

Low temperature gradient values are observed beneath the East European Platform, the Adriatic Sea and beneath the Bohemian massif.

\section{Optimized heat source distribution in the upper (granitic) crust}

Fig. 6 gives the results of the heat source distribution within the upper crust which is obtained when the calculated heat flow density fits best the observed heat flow density.

In general, the heat generation is smaller than $2.0 \mu \mathrm{W} / \mathrm{m}^{3}$. This is well in accordance with known values of the radioactive heat generation in granitic rocks.

The lateral variations are ranging between $<0.5$ and about $2.0 \mu \mathrm{W} / \mathrm{m}^{3}$. 


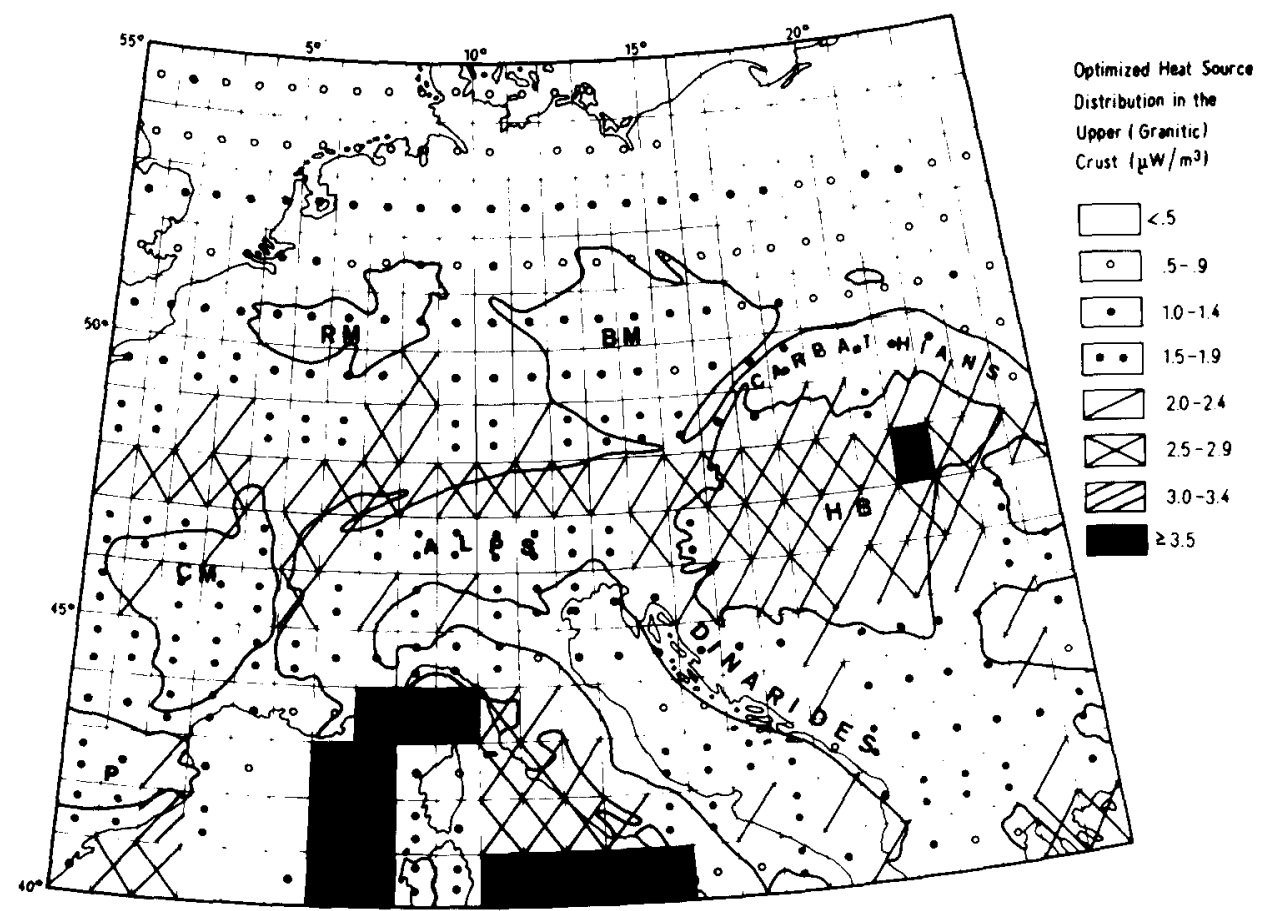

Fig. 6: Optimized heat source distribution in the upper (granitic) crust (in $\mu \mathrm{W} / \mathrm{m}^{3}$ ). $B M, C M, H B, P$, $R M$ see Fig. 1

The lowest values are obtained in the northeastern part of the studied area which is a part of the southwest border of the East European platform.

This result confirms that steady state heat conduction conditions can be taken as a basic model assumption.

On the other hand, there are obtained very high heat generation values beneath the Balearic and Tyrrhenian seas which are unrealistic when interpreting them in terms of radioactive heat generation in the upper crust.

Obviously, the basic assumption of steady state heat conduction does not hold for these areas and additional heat transport processes must be taken into account.

Taking the proposed method of source optimization it is possible to estimate for which areas the solution of the inverse problem on the basis of the steady state heat conduction equation is not allowed.

\section{REFERENCES}

Cermák, V.; Hurtig, E. (Eds.), 1977. Preliminary heat flow map of Europe. Geophysical Institute Czechosl. Acad. Sc., Praha.

Cermák, V., 1982. Crustal temperature and mantle heat flow in Europe. Tectonophysics, 83: $123-142$. 
Choudhury, M.; Giese, P.; Visintini, G. de, 1971. Crustal structure of the Alps: some general features from explosion seismology. Boll. Geofis. Teor. Appl., 13(51-52): 211-240.

Colombo, B.; Giese, P.; Luongo, G.; Morelli, C.; Riuscetti, M.; Scrarascia, S.; Schütte. K.-G.; Strowald, J.: Visintini, G. de., 1973. Preliminary report on the seismic refraction profile Gargano-SalernoPalermo-Pantelleria (1971). Boll. Geofis. Teor. Appl., 15(59): 225-254.

European Seismological Commission, Subcommission Deep Seismic Sounding, 1982. Activity Report 1980-1982, Leeds. In: Stiller, H.; van Gils, J. M.; Knoll, P. (Eds.). 1983. XXIII th General Assembly of the European Seismological Commission Vol I: 45-169. Potsdam.

Faber, S., 1978. Refraktionsseismische Untersuchungen der Lithosphäre unter den Britischen Inseln. Dissertation Univ. Karlsruhe.

Giese, P.: Morelli. C., 1973. La struttura della crosta terrestre in Italia. Acad. Naz. Lincei. No. 183 : 317-362.

Giese, P.; Morelli, C., 1974. European Seismological Commission, Subcommission Deep Seismic Sounding. Working Group for Southern and Western Europe, Activity Report 1972-1974, 23 pp.

Jubitz. K.-B. (Ed.), 1976. Materialien zum tektonischen Bau von Europa. Veröfl. Zl für Physik der Erde, No. 47.

Labrouste, Y. H.; Baltenberger, P.; Perrier, G.; Recq, M., 1968. Courbes d'égale profondeur de la discontinuité de Mohorovičic dans le Sud-Est de la France. C. R. Acad. Sc. Paris, 266: 663-665.

Makris. J., 1977. Geophysical investigations of the Hellenides. Hamburger Geophysikalische Einzelschriften, Nr. 33, 128 pp.

Miller, H.: Ansorge, J.; Aric, K.; Perrier, G., 1978. Preliminary results of the Lithospheric Seismic Alpine Longitudinal Profile, 1975, from France to Hungary. In: Closs, H.; Roeder, D.; Schmidt, K. (Eds.). Alps, Apennines, Hellenides. ICG Scient. Rep. 38, E. Schweizerbart'sche Verlagsbuchhandlung Stuttgart, 33-39.

Mueller, S.; Ansorge, J.; Egloff, R.; Kissling, E., 1980. A crustal cross section along the Swiss Geotraverse from the Rhinegraben to the Po Plain.

Eclogae Geol. Helv., 73: 463-485.

Mueller, S.; Prodehl, C.; Mendes, A.S.; Sousa Moreira, V., 1973. Crustal structure in the Southwestern part of the Iberian peninsula. Tectonophysics, 20: 307-318.

Recq, M., 1970. Courbes d'égale profondeur de la disccontinuité de Mohorovičić en Provence. C.R. Acad. Sc. Paris, 270: 11-13.

Sapin. M.: Hirn. A., 1974. Results of explosive seismology in the Southern Rhone valley. Ann. Geophys., 30: 181-202.

Schütte, K.-G., 1978. Crustal structure of Southern Italy. In: Closs, H.; Roeder, D.; Schmidt, K. (Eds.). Alps. Apennines. Hellenides, ICG Scient. Rep. 38, E. Schweizerbart'sche Verlagsbuchhandlung Stuttgart, 315-321.

Sollogub, V. B.; Guterch, A.; Prosen, D., 1978. Stroenie zemnoi kory i verchnei mantii central'noi i vostočnoi Evropy. Naukova Dumka, Kiev.

Stromeyer, D., 1984. Downward continuation of heat flow data by means of least squares methods. Tectonophysics, 103: 55-66.

Stromeyer, D.; Hurtig, E., 1983. Parameter estimation for steady-state heat conduction models. Zbl. Geol. Paläont. Teil I, H. 1/2: 93-101.

Weigel. W., 1974. Crustal structure under the Ionian Sea. J. Geophys., 40: 137-140. 